\title{
Quiz
}

\section{Die Seniorin unter den Wissenschaftsakademien}

Die Deutsche Akademie der Naturforscher Leopoldina ist die älteste dauerhaft existierende naturforschende Akademie der Welt. Namenspatron war Kaiser Leopold I. Gegründet 1652 als „Academia Naturae Curiosum" nimmt sie seit Juli 2008 die Aufgaben der deutschen Nationalen Akademie der Wissenschaften wahr. Aufgabe ist die Förderung der Wissenschaft durch nationale und internationale Zusammenarbeit, ihrer Tradition nach „zum Wohle des Menschen und der Natur". Die Mitgliederliste der Leopoldina verzeichnet viele berühmte Namen, z.B. Marie Curie, Albert Einstein, Niels Bohr, Francis Crick oder auch die internistischen Onkologen Volker Diehl und Klaus Höffken. Die Leopoldina vergibt zahllose Preise. Seit 2007 verleiht sie auch alle zwei Jahre den mit 15.000 Euro dotierten Thieme-Preis in der Medizin. Ausgezeichnet werden junge Wissenschaftlerinnen und Wissenschaftler, die wesentliche neue Erkenntnisse zur Ätiologie, Pathogenese, Therapie und Prävention menschlicher Erkrankungen erarbeitet haben. Zuletzt erhielt ihn 2011 der Dermatologe Priv.-Doz. Dr. Roland Wolf aus München.

\section{Der Buchstabe der richtigen Antwort ist}

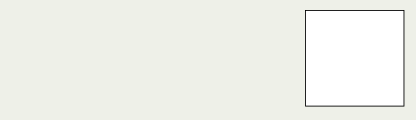

Name

Straße, Nr.

PLZ, Ort

Was ich noch sagen wollte ...

Coupon bitte ausfüllen und abschicken an Springer Medizin, Urban \& Vogel $\mathrm{GmbH}$

Redaktion Im Focus Onkologie - Quiz 11/2012

Aschauer Straße 30 • 81549 München

Oder senden Sie uns eine E-Mail an doris.berger@springer.com

Einsendeschluss: 17.12 .2012

\section{Und das können Sie gewinnen ...}

Alles, was Wissen schafft.

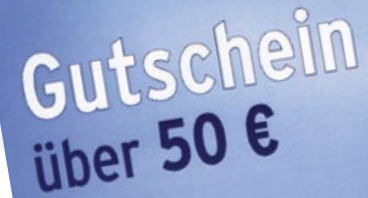

Q Springer Medizin

Unter den richtigen

Einsendungen verlosen

wir drei Gutscheine über

50 Euro, die Sie für ein

beliebiges Springer-Buch

einlösen können.

Einsendeschluss ist der

17.12.2012.
Wo wurde die heutige Leopoldina 1652 gegründet?

A In Erfurt In Frankfurt

In Schweinfurt
Das Hauptgebäude der Leopoldina dem Jägerberg in Halle, das ehemalige Logenhaus „Zu den drei Degen". 